\section{Oxidative DNA Damage is Induced by Chronic Cigarette Smoking, but Repaired by Abstention}

\author{
Teruo Inoue, ${ }^{*}, a$ Masatoshi Hayashi, ${ }^{b}$ \\ Kan Takayanagi, ${ }^{a}$ and Shigenori Morooka ${ }^{a}$
}

${ }^{a}$ Department of Cardiology and ${ }^{b}$ Department of Obstetrics and Gynecology, Koshigaya Hospital, Dokkyo University School of Medicine, 2-1-50, Minamikoshigaya, Koshigaya City, Saitama 343-8555, Japan

(Received November 28, 2002; Accepted February 5, 2003)

The association of chronic cigarette smoking and abstention with oxidative DNA damage was studied. The serum level of an oxidative DNA damage marker, 8-hydroxy-2'-deoxyguanosine (8-OHdG), was measured in 20 healthy male smokers and 8 healthy male non-smokers. The 8-OHdG level was significantly higher in the smokers than in the non-smokers $(0.22 \pm 0.05$ vs. $0.07 \pm 0.02 \mathrm{ng} / \mathrm{ml}, p<0.001)$. Ten of 20 smokers abstained from smoking for 4 weeks. Their 8-OHdG levels were significantly reduced by the smoking abstention $(0.27 \pm 0.05$ to $0.14 \pm 0.02 \mathrm{ng} / \mathrm{ml}$, $p<0.001$ ). The remaining 10 not only abstained from smoking, but also received $2 \mathrm{~g}$ /day of oral vitamin $C$. Their 8-OHdG levels were also significantly reduced $(0.27 \pm 0.05$ to $0.13 \pm 0.02 \mathrm{ng} / \mathrm{ml}, p<0.001)$. However, there was no significant difference in the serial changes in 8-OHdG level between the smoking abstention group and the smoking abstention with vitamin $\mathrm{C}$ supplementation group. These results suggest that chronic cigarette smoking enhanced oxidative DNA damage, but the damage was repaired by smoking abstention, and that vitamin $\mathrm{C}$ supplementation might not enhance the repair. In light of the DNA damage, smoking abstention should be encouraged.

Key words — 8-hydroxy-2'-deoxyguanosine, oxidative DNA damage, smoking, smoking abstention

\footnotetext{
*To whom correspondence should be addressed: Department of Cardiology, Koshigaya Hospital, Dokkyo University School of Medicine, 2-1-50, Minamikoshigaya, Koshigaya City, Saitama 343-8555, Japan. Tel.: +81-489-65-1111; Fax: +81-489-65-1128; E-mail: inouet@dokkyomed.ac.jp
}

\section{INTRODUCTION}

Cigarette smoking is a major source of production of exogenous pro-oxidants, reactive oxygen species and free radical generators, which are present in both gas and particulate phases. ${ }^{1)}$ Smoking results in an elevation of reactive oxygen species and the depletion of its scavengers in the circulating blood. ${ }^{1,2)}$ In this situation, in which the dynamic balance between pro-oxidation and anti-oxidation is shifted towards the former, oxidative stress occurs. Oxidative stress may lead to cell damage and malfunction through the free radical-mediated decomposition of vital molecules, such as DNA, proteins and lipids. ${ }^{3)}$ Lipid peroxidation is one of the most biologically important free-radical reactions. ${ }^{4)}$ If unopposed with an efficient local anti-oxidative defense system, peroxidative injury to the plasma phospholipids may lead to severe cell damage. On the other hand, DNA is also a major target of constant oxidative damage from endogeneous oxidants. Although numerous defense systems protect cellular macromolecules against oxidation, there is a high rate of damage to DNA. The DNA damage has been assessed by measuring the steady-state level of 8-hydroxy-2'deoxyguanosine $(8-\mathrm{OHdG})$ in DNA in various tissues. ${ }^{5-7)} 8-\mathrm{OHdG}$ is secreted into the blood stream and also into urine, ${ }^{6-8)}$ providing an estimate of the repair from damaged DNA. Measurement of its levels in both blood serum and urine has been possible using enzyme-linked immunosorbent assay (ELISA) $\left.{ }^{8}{ }^{89}\right)$ The purpose of this investigation was to study the association of chronic cigarette smoking, abstention and vitamin $\mathrm{C}$ supplemention with this marker for oxidative DNA damage.

\section{MATERIALS AND METHODS}

Study Protocol — Twenty healthy male smokers, who habitually smoked 20 cigarettes or more every day, were recruited as volunteers for this study. After 4 weeks' of observation for the control, the subjects were asked to abstain from smoking for 4 weeks. Ten ( $34 \pm 5$ years) of these subjects were asked to abstain from smoking only, and the remaining 10 ( $35 \pm 7$ years) also received $2 \mathrm{~g} /$ day of oral vitamin $\mathrm{C}$ by tablets during the 4 -week period of smoking abstention. Eight non-smokers (33 \pm 6 years) were also selected as control subjects. No subject was habitually given vitamin $\mathrm{E}$ in addition to vitamin $\mathrm{C}$, or any other anti-oxidant supple- 
ments. Blood samples were taken for the measurement of serum levels of 8-OHdG at the beginning of the study, at the end of the control period, and at the end of the 4-week period of smoking abstention. For the non-smokers, blood samples were taken once. All of the blood donors were required to be free from any drugs known to have antioxidative action for 14 days and for $48 \mathrm{hr}$ prior to blood collection. They were requested to eat a light meal on the night before blood collection, and to consume no food, fruit juice or caffeine-containing beverages in the morning of the blood collection day. These conditions were explained to all volunteers in advance, and written informed consent was obtained from all volunteers. The study protocol was approved by the ethics committee at our institute. Blood was collected under a fasting state early in the morning at each time period. A total of $10 \mathrm{ml}$ of blood was taken from each participant by venipuncture of the antecubital vein. Blood was immediately collected in a plain tube, and serum was separated by centrifugation at $3000 \times g$ for $20 \mathrm{~min}$.

Determination of Serum 8-OHdG Level — Before each 8-OHdG assay, serum samples were again separated by centrifugal ultrafiltration at $1500 \times \mathrm{g}$ for 60 min using ULTRACENT-10 (Toso Co., Ltd., Tokyo, Japan). The filtration samples were used to determine $8-\mathrm{OHdG}$ with a competitive ELISA kit (8-OHdG Check, Japan Institute for the Control of Aging, Fukuroi, Shizuoka, Japan). Microtiter ELISA plates were precoated with $8-\mathrm{OHdG}$. Fifty microliters of the filtration sample and an 8-OHdG monoclonal antibody were added to each well, and they were incubated at $4^{\circ} \mathrm{C}$ for $18 \mathrm{hr}$. After the wells were washed 3 times, enzyme-labeled peroxidase (POD)anti-mouse $\mathrm{IgG}$ was added, followed by incubation at $37^{\circ} \mathrm{C}$ for $60 \mathrm{~min}$. The wells were again washed 3 times. Next, a substrate containing 3,3',5,5'tetramethylbenzidine (TMBZ) was added, and the wells were incubated at room temperature for $15 \mathrm{~min}$. The reaction was stopped by $1 \mathrm{M}$ phosphoric acid. The absorbance was read at a wavelength of $450 \mathrm{~nm}$. The specificity of the monoclonal antibody used in the competitive ELISA kit has been established. Inter- and intra-assay variances for the procedure were $10.2 \%$ and $9.5 \%$, respectively.

Statistical Analysis — Data are expressed as means \pm S.D. Inter-group comparisons for continuous variables were performed with unpaired $t$-tests. Intra-group comparisons at each blood sampling point were performed using repeated measures analysis of variance (ANOVA). $p<0.05$ was con-

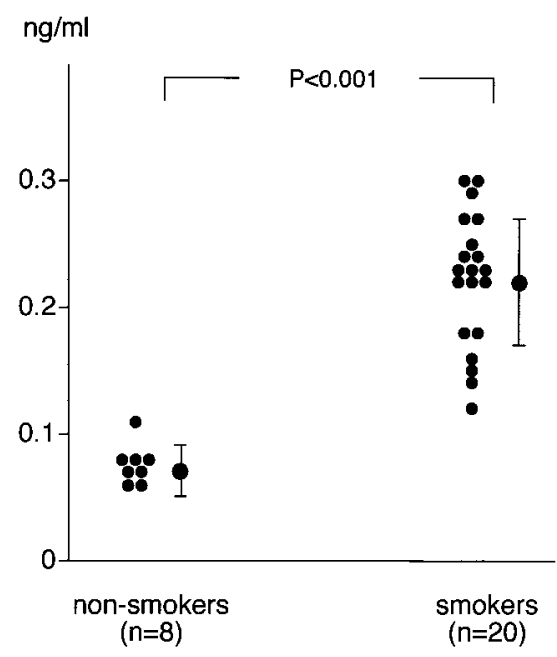

Fig. 1. Comparison of the Serum 8-OHdG Level between Smokers and Non-Smokers

The level was significantly higher in smokers than in non-smokers. Closed circles with bars indicate means \pm S.D. 8-OHdG: 8-hydroxy-2'deoxyguanosine.

sidered significant.

\section{RESULTS}

In the 20 smokers, the serum 8 -OHdG level was $0.22 \pm 0.05 \mathrm{ng} / \mathrm{ml}$ at the beginning of study, which was significantly higher $(p<0.001)$ than the value of $0.07 \pm 0.02$ in the 8 non-smokers (Fig. 1). There was no significant difference in the values at the beginning of the study between the groups with smoking abstention $(n=10)$ and smoking abstention with vitamin $C$ supplementation $(n=10)(0.23 \pm 0.06 v s$. $0.24 \pm 0.03 \mathrm{ng} / \mathrm{ml}$ ). In both groups, the values did not change at the end of the control period $(0.27 \pm 0.05$ and $0.27 \pm 0.05 \mathrm{ng} / \mathrm{ml}$, respectively in the smoking abstention group and the smoking abstention with vitamin $\mathrm{C}$ supplementation group), but significantly decreased in both at the end of the 4week period of smoking abstention $(0.14 \pm 0.02$, $p<0.001$ and $0.13 \pm 0.02 \mathrm{ng} / \mathrm{ml}, p<0.001$, respectively). There was no significant difference in the serial changes between the groups with and without vitamin C supplementation (Fig. 2).

\section{DISCUSSION}

In this study we demonstrated that the serum 8OHdG level was higher in smokers than in nonsmokers, and that the 8-OHdG level in the smokers 


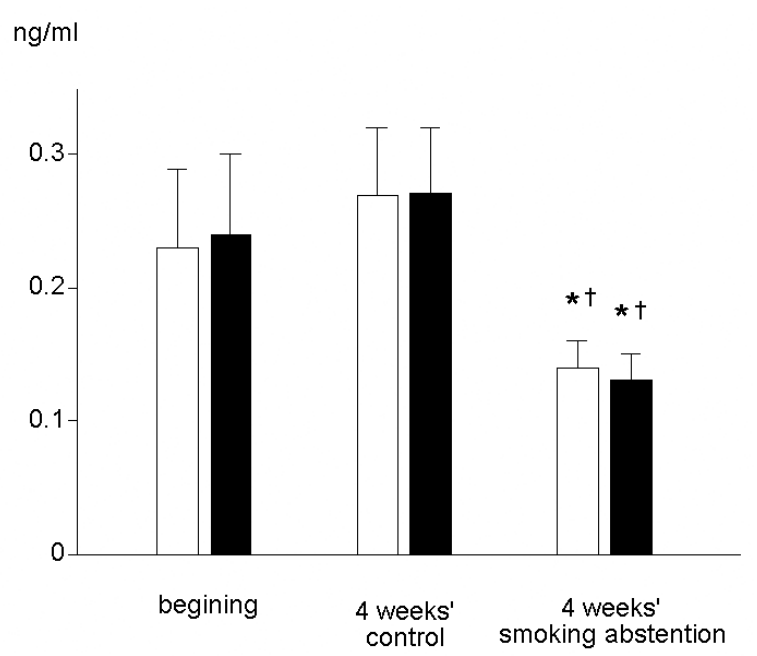

Fig. 2. Serial Changes in the Serum 8-OHdG Levels between the Smoking Abstention Group (Open Square) and the Smoking Abstention with Vitamin C Supplementation Group (Closed Square)

There was no significant difference in the values at the beginning of the study between the two groups. In both groups, the values did not change at the end of the control period, but significantly decreased at the end of the 4-week smoking abstention. There was no significant difference in the serial changes between the groups. ${ }^{*} p<0.001 v s$. beginning, $\dagger p<0.001 v s .4$ weeks' control.

was decreased to a level equivalent to that of nonsmokers by 4 weeks of smoking cessation. The decrease in the 8-OHdG levels resulting from smoking abstention was not modulated by vitamin $\mathrm{C}$ supplementation. These results suggest that oxidative DNA damage was induced by habitual cigarette smoking, but was repaired by abstention and that the repair was independent of vitamin $C$ supplementation.

It has been proposed that biological damage caused by reactive oxygen species, such as superoxide radical, singlet oxygen, hydrogen peroxide, and the hydroxyl radical, contributes to aging and various diseases, such as cancer and heart disease. ${ }^{10-12)}$ These oxygen species are formed in vivo as byproducts and intermediates of aerobic metabolism and during oxidative stress. Numerous defense systems protect cellular macromolecules against oxidation; nevertheless, there is a high rate of damage to DNA. ${ }^{13)}$ The oxidized DNA is continuously repaired, and the oxidized bases are excreted into the blood serum and then the urine. The oxidized nucleoside, $8-\mathrm{OHdG}$, is one of the known oxidative DNA damage products. The $8-\mathrm{OHdG}$ levels have been measured in DNA isolated from various organ tissues. ${ }^{6,7)}$ Recently, its urinary levels have been determined by high performance liquid chromatography
(HPLC). ${ }^{14)}$ More recently, a monoclonal antibody specific for 8-OHdG has been developed, and an ELISA system for serum or urinary 8-OHdG determination constructed. ${ }^{899}$ The measurement of the serum or urinary $8-\mathrm{OHdG}$ levels provides some information on the effects of various degrees of oxidative stress on DNA level, differently from other oxidative stress markers, such as lipid peroxidation markers, including thiobarbituric acid-reactive substances (TBARS) ${ }^{15)}$ or $\mathrm{F}_{2}$-isoprostanes. ${ }^{16)}$

Cigarette smoking is a well-known inducer of oxidative stress, which often results in increased lipid peroxidation. Enhanced circulating levels and urinary excretion of $\mathrm{F}_{2}$-isoprostanes have been reported in smokers in association with increased levels of oxidative stress. ${ }^{17)}$ On the other hand, the increased serum level of $8-\mathrm{OHdG}$ in smokers in our results suggests that tissue damage caused by smoking-induced oxidative stress extends to the DNA level. Increased urinary 8-OHdG excretion in smokers has already been reported by several investigators. ${ }^{18,19)}$ However, to the best of our knowledge, our study might be the first to demonstrate that oxidative DNA damage is repaired by smoking abstention. It is suggested in smokers that the activity of O6alkylguanine-DNA-alkyltransferase, a DNA repair enzyme, decreases, compared with that in non-smokers. ${ }^{20)}$ Thus, smoking abstention may lead not only to a reduction of oxidative DNA damage progression but also to accelerating some DNA repair enzymes.

Vitamin $\mathrm{C}$ is known to be an anti-oxidant supplement. However, the effect of vitamin $\mathrm{C}$ on $8-\mathrm{OHdG}$ formation has remained controversial. Fraga et al. ${ }^{21)}$ reported that a high intake of vitamin $\mathrm{C}$ protected against 8-OHdG formation in human seminal DNA. In contrast, Loft et al. ${ }^{18)}$ demonstrated that the intake of vitamin $\mathrm{C}$ was not correlated with $8-\mathrm{OHdG}$ excretion. In our results, vitamin $\mathrm{C}$ supplementation did not appear to produce any additional reduction of oxidative DNA damage beyond that attributable to smoking abstention.

In conclusion, chronic cigarette smoking enhanced oxidative DNA damage, as reflected by the serum 8-OHdG level, but the damage was decreased to the non-smokers' level by smoking abstention. In light of the DNA damage, smoking abstention should be encouraged.

Acknowledgements We gratefully acknowledge the technical support services provided by $\mathrm{Mr}$. Minoru Sasaki, Tanabe Seiyaku Co., Ltd. (Osaka, 
Japan). We thank Mr. Hiroshi Endo, Tanabe R\&D Corporation (Toda, Saitama, Japan), for the ELISA assay of 8-OHDG.

\section{REFERENCES}

1) Frei, B., Forte, T. M., Ames, B. N. and Cross, C. E. (1991) Gas phase oxidants of cigarette smoke induce lipid peroxidation and changes in lipoprotein properties in human blood plasma: protective effects of ascorbic acid. Biochem. J., 277, 133-138.

2) Zhou, J. F., Yan, X. F., Guo, F. Z., Sun, N. Y., Qian, Z. J. and Ding, D. Y. (2000) Effects of cigarette smoking and smoking cessation on plasma constituents and enzyme activities related to oxidative stress. Biomed. Environ. Sci., 13, 44-55.

3) Finkel, T. and Holbrook, N. J. (2000) Oxidants, oxidative stress and the biology of aging. Nature (London), 408, 239-247.

4) Yagi, K. (1994) Lipid peroxides and related radicals in clinical medicine. In Free Radicals in Diagnostic Medicine (Armstrong, D., ed.), Plenum Press, New York, pp. 1-14.

5) Richter, C., Park, J. W. and Ames, B. N. (1988) Normal oxidative damage to mitochondrial and nuclear DNA is extensive. Proc. Natl. Acad. Sci. U.S.A., 85, 6465-6467.

6) Kasai, H., Crain, P. F., Kuchino, Y., Nishimura, S., Ootsuyama, A. and Tanooka, H. (1986) Formation of 8-hydroxyguanine moiety in cellular DNA by agents producing oxygen radicals and evidence for its repair. Carcinogenesis, 7, 1849-1851.

7) Kasai, H., Nishimura, S., Kurokawa, Y. and Hayashi, Y. (1987) Oral administration of the renal carcinogen, potassium bromate, specifically produces 8-hydroxydeoxyguanosine in rat target organ DNA. Carcinogenesis, 8, 1959-1961.

8) Yin, B., Whyatt, R. M., Perera, F. P., Randall, M. C., Cooper, T. B. and Santella, R. M. (1995) Determination of 8-hydroxydeoxyguanosine by an immunoaffinity chromatography-monoclonal antibody-based ELISA. Free Radic. Biol. Med., 18, 1023-1032.

9) Inoue, T., Inoue, K., Maeda. H., Takayanagi, K. and Morooka, S. (2001) Immunological response to oxidized LDL occurs in association with oxidative DNA damage independently of serum LDL concentrations in dyslipidemic patients. Clin. Chim. Acta, 305, 115-121.

10) Kanofsky, J. R., Hoogland, H., Wever, R. and Weiss, S. J. (1988) Singlet oxygen production by human eosinophils. J. Biol. Chem., 263, 9692-9696.
11) Ames, B. N. (1983) Dietary carcinogens and anticarcinogens. Oxygen radicals and degenerative diseases. Science, 221, 1256-1264.

12) Steinberg, D., Partharathy, S., Carew, T. E., Khoo, J. C. and Witztum, M. D. (1989) Beyond cholesterol. Modifications of low-density lipoprotein that increase its atherogenicity. N. Engl. J. Med., 320, 915-924.

13) Richter, C., Park, J. W. and Ames, B. N. (1988) Normal oxidative damage to mitochondrial and nuclear DNA is extensive. Proc. Natl. Acad. Sci. U.S.A., 85, 6465-6467.

14) Floyd, R. A., Watson, J. J., Wong, P. K., Altmiller, D. H. and Rickard, R. C. (1986) Hydroxyl free radical adduct of deoxyguanosine: sensitive detection and mechanisms of formation. Free Radic. Res. Commun., 1, 163-172.

15) Witztum, J. L. and Steinberg, D. (1991) Role of oxidized low density lipoprotein in atherogenesis. J. Clin. Invest., 88, 1785-1792.

16) Patrono, C. and FitzGerald, G. A. (1997) Isoprostanes: potential markers of oxidant stress in atherothrombotic disease. Arterioscler. Thromb. Vasc. Biol., 17, 2309-2315.

17) Morrow, J., Frei, B., Longmire, A. W., Gaziano, J. M., Lynch, S. M., Shyr, Y., Strauss, W. E., Oates, J. A. and Roberts, L. J. (1995) Increase in circulating products of lipid peroxidation (F2-isoprostanes) in smokers. N. Engl. J. Med., 332, 1198-1203.

18) Loft, S., Vistisen, K., Ewertz, M., Tjonneland, A., Overvad, K. and Poulsen, H. E. (1992) Oxidative DNA damage estimated by 8-hydroxydeoxyguanosine excretion in humans: influence of smoking, gender and body mass index. Carcinogenesis, 13, 2241-2147.

19) Tagesson, C., Kallberg, M. and Leanderson, P. (1992) Determination of urinary 8-hydroxydeoxyguanosine by coupled-column high-performance liquid chromatography with electrochemical detection: a noninvasive assay for in vivo oxidative DNA damage in humans. Toxicol. Meth., 1, 242251.

20) Boffetta, P., Nyberg, F., Mukerita, A., Benhamou, S., Constantinescu, V., Batura-Gabryel, H., BruskeHohlfeld, I., Schmid, G., Simonato, L., Pelkonen, P. and Hall, J. (2002) O6-Alkylguanine-DNAalkyltransferase activity in peripheral leukocytes, smoking and ris of lung cancer. Cancer Lett., 180, 33-39.

21) Fraga, C. G., Motchnik, P. A., Shigenaga, M. K., Helbock, H. J., Jacob, R. A. and Ames, B. N. (1991) Ascorbic acid protects against endogenous oxidative DNA damage in human sperm. Proc. Natl. Acad. Sci. U.S.A., 88, 11003-11006. 